\title{
Boat anchoring contributes substantially to coral reef degradation in the British Virgin Islands
}

\author{
Rebecca L Flynn ${ }^{\text {Equal first author, } 1}$, Graham E Forrester ${ }^{\text {Corresp. Equal first author, } 1}$ \\ ${ }^{1}$ Department of Natural Resources Science, University of Rhode Island, Kingston, RI, United States \\ Corresponding Author: Graham E Forrester \\ Email address: gforrester@uri.edu
}

Community decline is often linked to anthropogenic activities. Coral reef declines, for example, have been linked to overfishing and climate change, but impacts of coastal development, pollution, and tourism have received increasing attention. Here, we isolated the impact of one little-studied aspect of recreational activity on coral reefs - damage from boat anchoring - by performing a survey of 24 sites in the British Virgin Islands (BVI) subject to varying levels of anchoring activity. The percent cover of hard corals and sea fans was reduced by a factor of $\sim 1.7$ and $\sim 2.6$ respectively at highly anchored sites. Hard coral colonies were $\sim 40 \%$ smaller in surface area and $\sim 60 \%$ less dense at sites experiencing high anchoring frequency. In addition, highly anchored sites supported only $\sim 60 \%$ of the species richness of little anchored sites. Frequently anchored sites were $\sim 60 \%$ as structurally complex and supported less than half as many fish as those rarely anchored, with 5 of 7 fish functional groups affected. Roughly $24 \%$ of BVI coral reef by area appears suitable for anchoring, suggesting that impacts associated with boat anchoring may be both locally severe and more pervasive than previously appreciated. 


\section{Boat anchoring contributes substantially to coral reef \\ 2 degradation in the British Virgin Islands}

4 Rebecca L. Flynn ${ }^{1}$ and Graham E. Forrester ${ }^{1}$

5 'University of Rhode Island, Department of Natural Resources Science, Kingston, RI 02881

7 Corresponding Author:

8 Graham Forrester

9 University of Rhode Island, Department of Natural Resources Science, Kingston, RI 02881

10 Email address: gforrester@uri.edu

Abstract

Community decline is often linked to anthropogenic activities. Coral reef declines, for example, pollution, and tourism have received increasing attention. Here, we isolated the impact of one little-studied aspect of recreational activity on coral reefs - damage from boat anchoring - by performing a survey of 24 sites in the British Virgin Islands (BVI) subject to varying levels of anchoring activity. The percent cover of hard corals and sea fans was reduced by a factor of $\sim 1.7$ and $\sim 2.6$ respectively at highly anchored sites. Hard coral colonies were $\sim 40 \%$ smaller in surface area and $\sim 60 \%$ less dense at sites experiencing high anchoring frequency. In addition, highly anchored sites supported only $\sim 60 \%$ of the species richness of little anchored sites. Frequently anchored sites were $\sim 60 \%$ as structurally complex and supported less than half as many fish as those rarely anchored, with 5 of 7 fish functional groups affected. Roughly $24 \%$ of BVI coral reef by area appears suitable for anchoring, suggesting that impacts associated with boat anchoring may be both locally severe and more pervasive than previously appreciated.

\section{Introduction}

Human activities are degrading habitats on a global scale, resulting in a loss of biodiversity, trophic collapse, and diminished ecosystem function and services (Ehrlich \& Wilson, 1991; Naeem et al., 1994; Dobson et al., 2006). Coral reefs, in particular, are high diversity habitats accounting for approximately one quarter of the ocean's biodiversity while occupying less than $0.01 \%$ of the marine environment (Burke et al., 2011). Reefs perform several ecosystem services by protecting shorelines, supplying fisheries, and attracting tourism and recreation that provide nations with revenue (Burke et al., 2011). Coral reefs are, however, declining globally (Gardner et al., 2003; Schutte, Selig \& Bruno, 2010) and losing three-dimensional complexity (AlvarezFilip et al., 2009). Both diminishing coral cover and complexity negatively impact reef fish, 
37 some of which rely on live coral for food while others utilize the structure as refuge (Lewis, 38 1998; Graham et al., 2009).

39 Reef degradation is caused by the integrative effects of natural disturbances, such as hurricanes, and anthropogenic stressors (Wilkinson \& Buddemeier, 1994; Wilkinson, 2008). Key anthropogenic stressors include global climate change (ocean warming and acidification) and local effects from invasive species, overfishing, coastal pollution and other symptoms of increasing human population density (Wilkinson, 2008; Jackson et al., 2014). Boat anchoring is one symptom of increasing human visitation (Jackson et al., 2014) that may contribute to reef degradation. As ocean recreation and the associated boat traffic increase rapidly in many areas of the world (Davenport \& Davenport, 2006; Burgin \& Hardiman, 2011), physical damage to reefs may also increase. Physical damage from boat anchors and the associated chains (hereafter, collectively referred to as anchors or anchoring) is an acknowledged source of damage to coral reefs (Goenaga, 1991). Compared to other human impacts, however, boat anchoring has been the subject of virtually no formal study (Johnstone, Muhando \& Francis, 1998). By way of illustration, a search of Web of Science for "coral reef and anchor" returned only 68 papers, whereas a search for "coral reef and climate" returned 2,335 and one for "coral reef and fishing" returned 6,234.

Previous studies have rarely addressed the community-wide impacts from chronic anchor damage. Our objective was, therefore, to quantify effects of chronic anchor damage to coral reefs through a replicated comparison of anchor-damaged and undamaged reefs. We assessed both the direct impacts on sessile species like corals and sea fans, and the indirect effects on reefassociated fishes. We expected that reefs that have experienced higher anchoring activity would support fewer and smaller corals. Consequently, we also expected anchor-damaged reefs would have lower structural complexity and lower densities of reef-associated fishes.

\section{Materials and Methods}

\section{Study Location}

We studied the effects of anchoring on reefs in the British Virgin Islands (BVI) because the number of active vessels and their size contribute to a high risk of anchor damage to reef habitats in this territory. Approximately $1100-1500$ yachts (12-16 m in length) operate in the $155 \mathrm{~km}^{2}$ of BVI water. This fleet is expanding and visitation by larger mega-yachts exceeding $45 \mathrm{~m}$ in length is increasing (personal communication with Janet Oliver, BVI Charter Yacht Society, and Trish Baily, BVI Association of Reef Keepers and BVI ReefCheck).

\section{Study Design}

We surveyed 24 reefs (each $0.5-0.75$ ha in area) during the summer of 2014 to determine the effects of chronic anchoring. Sites were categorized as experiencing little or no anchoring (hereafter low, $\mathrm{n}=11$ ), occasional anchoring (hereafter medium, $\mathrm{n}=3$ ) or regular anchoring (hereafter high, $\mathrm{n}=10$ ) (Fig. 1). Site selection and classification was based primarily on the plausibility of use as an anchorage and expert opinion about the level of anchoring activity. We selected a set of candidate sites that were plausible anchorages because they were situated on the leeward sides of islands, usually near sand, and often in bays. We also selected candidate sites we considered unlikely to be used as anchorages because, despite being on the leeward side of islands, they were locations likely to be unsafe (e.g. near a cliff) or undesirable (e.g. subject to heavy powerboat traffic) anchorages. We consulted seven local experts who all had $>10$ years of 
80 experience with boating activity in the BVI (dive instructors, charter captains, and marine 81 conservation professionals) to classify sites. High- and low-anchoring sites were those for which 82 all 7 experts agreed on the extent of anchoring. Medium-anchoring sites were those for which 83 there were differences of opinion among local experts about the frequency of anchoring and, 84 although they represent a less clearly-resolved category, we retained them for our surveys.

85 We performed two post-hoc checks to corroborate the classification of anchoring activity and to 86 clarify the status of medium-anchoring sites. First, we quantified the observed density of yachts 87 using satellite images of each site (Fig. S1). We used all available images from 2004-2014 that 88 were not obscured by clouds $(n=4-10$ images per site). There were boat moorings at some sites but, because we knew the locations of moorings, we could distinguish moored boats from those at anchor. Although the images provided a far smaller sample of observations than the collective observations of local experts, we predicted that mean yacht densities in the images would differ among low-, medium-, and high-anchoring sites. Secondly, during our SCUBA surveys at each site we quantified symptoms of anchor damage (described further below) and tested whether they occurred at different frequencies among low-, medium- and high-anchoring sites.

To control for other sources of variation among sites, we selected sites that were similar in depth, wave exposure, and reef slope. In addition, we selected low- and high-anchoring sites in 10 groups that were close in proximity to further reduce the possibility that factors other than anchoring, particularly those associated with land-based human activity, differed among sites (Fig. 1). As a post-hoc check that we had not inadvertently created a bias among treatments by confounding anchoring with effects of land-based human activity, we used satellite images to measure the distance from the center of each reef site to the nearest shore and to the nearest developed land area (Lirman \& Fong, 2007) (Fig. S2).

Finally, to determine what percentage of reef in the BVI is potentially vulnerable to anchoring we used GIS to classify coral reefs by exposure (leeward or windward), based on the assumption that only leeward reefs are potential anchoring sites. The GIS feature class utilized was a benthic habitat map showing areas of the sea floor covered by coral reef, seagrass, hard bottom, and algae (NOAA et al., 2001). We isolated the coral reef polygons, created a new geodatabase feature class of those areas, and edited the attribute table to include categories for leeward or windward exposure (Environmental Systems Research Institute (ESRI), 2011).

Survey Methods

111 We sampled each site on SCUBA using 3-8 haphazardly placed 30-m transects. We used the 112 point-intercept method to estimate the percent cover of major benthic taxa, including live hard

113 coral; sea fans; branching soft corals; fleshy, filamentous, calcareous and crustose algae; erect 114 and encrusting sponges; and substrates, such as sand and rubble (Almada-Villela et al., 2003). In 115 addition, all scleractinian coral colonies intersected by the transect tape were identified to 116 species, classified by morphology, and measured in length $(\mathrm{L})$ and maximum orthogonal width 117 (W). Colony surface area (SA) was calculated assuming colonies were elliptical (SA $=0.5 \mathrm{~L} \mathrm{x}$ $1180.5 \mathrm{~W} \times \pi)$. We calculated coral colony density using the Strong Method, in which density 119 (organisms per $\left.\mathrm{m}^{2}\right)=\Sigma(1 / \mathrm{M})$ (unit area/total transect length) where $\mathrm{M}$ is the maximum orthogonal 120 width (Strong, 1966; Bakus, 2002). We also calculated the number of coral species intercepted 121 per transect, as a simple estimate of species richness that is adjusted for sampling effort. All 122 individuals of the most common sea fan (Gorgonia ventalina) within a $30 \times 1$-m belt transect 123 were counted and measured for height and width. 
124 As a post-hoc check of our classification of anchoring activity at each site, we quantified

125 symptoms consistent with recent anchor damage. For corals, we counted the number of colonies

126 that were newly overturned, broken, or scarred with gouges that were consistent with being

127 scraped by an anchor or chain. For sea fans, we counted the number of colonies that were

128 recently bent or broken at the base, or contained large rips in colony tissue with no associated

129 symptoms of disease.

130 To quantify the indirect effects of anchoring, we assessed reef complexity and fish population

131 densities. The three-dimensional structural complexity (or rugosity) was estimated for each

132 transect using the consecutive height difference method, for which the height of the tape off the

133 bottom is measured every $50 \mathrm{~cm}$ and the square root of the sum of the squared differences

134 between successive height measurements is used to describe vertical complexity (McCormick,

135 1994). Reef-associated fish were counted using $30 \times 1.5 \mathrm{~m}$ belt transects $\left(45 \mathrm{~m}^{2}\right.$ in area). We

136 counted all small- to medium-sized diurnal fish species, excluding very small cryptic benthic

137 species (e.g., some gobies and blennies) and very mobile mid-water species (e.g., jacks). Each

138 fish species was classified by both size (juveniles $=$ individuals judged to be $<1$ month post-

139 settlement, usually $<3 \mathrm{~cm}$ in total length; adults $=$ all larger individuals) and trophically based

140 functional group (macrocarnivores, piscivores, mobile benthic invertivores, sand invertivores,

$141 \mathrm{coral} / \mathrm{colonial}$ invertivores, spongivores, diurnal planktivores, nocturnal planktivores, territorial

142 gardeners, turf grazers, scrapers, excavator/eroders, macroalgae grazers, general omnivores)

143 (Halpern \& Floeter, 2008).

\section{Statistical Analyses}

145 All statistical analyses were done using site means as replicates because chronic anchor damage

146 is more appropriately assessed at the site-level than the transect-level, and because sites are a

147 meaningful unit for management. We tested effects of two categorical factors: anchoring activity

148 (a fixed factor with 3 levels: high (H), medium (M), and low (L)), and group (a random effect

149 with 10 levels). Although sea fans were included in all surveys for benthic cover, specific

150 measurements of sea fan density and size were made at fewer sites $(n=15)$. These 15 sites were

151 classified as high $\left(\mathrm{n}_{\mathrm{H}}=8\right)$ or low $\left(\mathrm{n}_{\mathrm{L}}=7\right)$ anchoring.

152 When data conformed to the assumptions of analysis of variance (ANOVA), we used

153 randomized block ANOVAs to assess the impact of anchoring while accounting for effects of

154 geographic proximity (group), and pairwise comparisons between anchoring activity levels (H-L,

155 H-M, L-M) were made using least squares means (LSM). When data did not conform to the

156 ANOVA assumption of normality, we were sometimes able to transform the data so that the

157 assumptions were met. In other cases, we used either nonparametric Kruskal-Wallis (K-W) tests

158 with Nemenyi post-hoc tests or Maximum Likelihood Estimation (MLE) models using

159 appropriate distributions to model the variance. For MLE models, changes in goodness-of-fit

160 statistics are typically used to evaluate the contribution of subsets of explanatory variables to a

161 particular model, so MLE models were fitted with anchoring only, group only, and both

162 anchoring and group as factors. These models were then compared using Akaike Information

163 Criterion (AIC) and the parameters from the best fitting model were used to calculate means and

164 standard errors for an intuitive presentation of results (Bolker, 2008). MLE models for

165 proportion data utilized a beta distribution with parameters ' $a$ ' and ' $b$,' from which we calculated

166 the mean $(a /(a+b))$ and the variance $\left(a b /\left((a+b)^{2}(a+b+1)\right)\right.$. MLE models for data that were positive

167 and continuous utilized gamma and lognormal distributions. The gamma distribution resulted in

168 's' (scale) and ' $a$ ' (shape) parameters, with which we calculated means (as) and variances ( $\left(\mathrm{s}^{2}\right)$. 
169 The lognormal distribution provided $\mu$ and $\sigma$ parameters, with which we calculated means

$170\left(\exp \left(\mu+\sigma^{2} / 2\right)\right)$ and variances $\left(\exp \left(2 \mu+\sigma^{2}\right)\left(\exp \left(\sigma^{2}\right)-1\right)\right)$. Standard error was calculated as the square

171 root of the variance. We report details of test results in a table (Table S1) and list only relevant p-

172 values for pairwise comparisons between levels of anchoring activity in the text. For ease of

173 interpretation and comparison between anchoring intensities, we have reported parameter

174 estimates, z-values, and p-values only from models comparing across anchoring levels. All

175 analyses were conducted in R v. 3.0.2 (R Core Team, 2013), using packages 'bbmle', 'Ismeans'

176 and 'PMCMR'.

\section{Results}

\section{Checking the classification of anchoring activity and confounding with land-based impacts}

179 The observed density of anchored yachts and frequency of anchor damage symptoms

180 corroborated the expert-based classification of anchoring activity. Based on surveys of satellite imagery, there were more boats anchored at sites classified as high anchoring than either medium or low anchoring ( $\mathrm{p}<0.0001)$ (Fig. 2). On the reef itself, high anchoring sites also showed the most signs of apparent anchor damage. We encountered more overturned scleractinian corals $\left(\mathrm{p}_{\mathrm{H}-}\right.$ $\mathrm{L}=0.046)$, broken scleractinian corals $\left(\mathrm{p}_{\mathrm{H}-\mathrm{L}}=0.048\right)$, and broken gorgonians $\left(\mathrm{p}_{\mathrm{H}-\mathrm{L}}=0.002\right)$ at high-anchoring sites, and these symptoms were substantially reduced at low-anchoring sites (Fig. S3). Overall, the post-hoc checks corroborated the distinction between low-and high-anchoring sites, and confirmed that, although the 3 medium-anchoring sites show intermediate levels of damage symptoms (Fig. S3), they cannot be conclusively separated from high- and lowanchoring sites.

We also confirmed that there were no apparent differences in proximity to land-based stressors. The low-, medium-, and high-anchoring sites were at similar distances from both land $(\mathrm{p}=0.60)$ and development $(\mathrm{p}=0.75)$ (Fig. S4).

\section{Responses of benthic taxa associated with anchoring}

Of the taxa whose benthic cover was surveyed, only hard corals and sea fans showed a significant response to anchoring activity (Table 1). Hard coral cover at highly anchored sites was reduced by a factor of roughly 1.7 relative to sites experiencing medium or little anchoring $\left(\mathrm{p}_{\mathrm{M}-\mathrm{H}}=0.047, \mathrm{p}_{\mathrm{L}-\mathrm{H}}=0.02, \mathrm{p}_{\mathrm{L}-\mathrm{M}}=0.89\right)$ (Fig. 3). Sea fan cover at sites with high and medium levels of anchoring was reduced by a factor of 2.6 compared to low-anchoring sites ( $\mathrm{p}_{\mathrm{M}-\mathrm{H}}=0.9$, $\mathrm{p}_{\mathrm{L}-\mathrm{H}}=0.044, \mathrm{p}_{\mathrm{L}-\mathrm{M}}=0.049$ ) (Fig. 3).

\section{Responses of coral populations associated with anchoring}

Coral colonies were approximately $39 \%$ smaller at sites with high levels of anchoring activity than at sites with medium or low levels $\left(\mathrm{p}_{\mathrm{L}-\mathrm{H}}=0.046, \mathrm{p}_{\mathrm{M}-\mathrm{H}}=0.28, \mathrm{p}_{\mathrm{L}-\mathrm{M}}=0.996\right)$ (Fig. 4$)$. In addition, coral colony density was roughly $57 \%$ lower at sites with high anchoring than at sites with little or no anchoring $\left(\mathrm{p}_{\mathrm{L}-\mathrm{H}}=0.0003, \mathrm{p}_{\mathrm{M}-\mathrm{H}}=0.55, \mathrm{p}_{\mathrm{L}-\mathrm{M}}=0.068\right)$ (Fig. 4). Coral species richness was also reduced by approximately $42 \%$ at sites with higher anchoring activity (either medium or high) than those with low levels ( $\mathrm{p}_{\mathrm{H}-\mathrm{L}}=0.0002, \mathrm{p}_{\mathrm{H}-\mathrm{M}}=0.94, \mathrm{p}_{\mathrm{L}-\mathrm{M}}=0.01$ ) (Fig. 4).

207

208 anchoring (Table S2). Branching corals included Acropora cervicornis, Madracis decactis, Porites divaricata, P. furcata, and P. porites; mounding corals were primarily Dichocoenia stokesii, Favia fragum, Madracis pharensis, Montastraea cavernosa, Orbicella annularis, $O$. 
211 faveolata, $O$. franksii, $P$. astreoides, Siderastrea radians, and $S$. siderea, and plate corals were

212 Agaricia agaricites, $A$. humilis, and A. lamarcki. Branching corals were roughly $65 \%$ smaller in

213 size $(\mathrm{p}=0.05)$ and their colony density was reduced by approximately $67 \%$ at high anchoring

214 sites than at low-anchoring sites $\left(\mathrm{p}_{\mathrm{H}-\mathrm{L}}=0.041, \mathrm{p}_{\mathrm{H}-\mathrm{M}}=0.97, \mathrm{p}_{\mathrm{L}-\mathrm{M}}=0.37\right)$. Similarly, both the

215 colony surface area $\left(\mathrm{p}_{\mathrm{H}-\mathrm{L}}<0.0001, \mathrm{p}_{\mathrm{H}-\mathrm{M}}=0.03, \mathrm{p}_{\mathrm{L}-\mathrm{M}}=0.65\right)$ and colony densities $\left(\mathrm{p}_{\mathrm{L}-\mathrm{H}}=0.002\right.$,

$\left.216 \mathrm{p}_{\mathrm{M}-\mathrm{H}}=0.69 ; \mathrm{p}_{\mathrm{M}-\mathrm{L}}=0.10\right)$ of mounding corals were reduced by roughly half at sites with high

217 anchoring. Plate coral surface area did not differ between anchoring intensities (Table S2), but

218 colony density was $55 \%$ lower at high anchoring sites $\left(\mathrm{p}_{\mathrm{L}-\mathrm{H}}=0.026, \mathrm{p}_{\mathrm{M}-\mathrm{H}}=0.61, \mathrm{p}_{\mathrm{M}-\mathrm{L}}=0.03\right)$.

219 Brain corals, cup-like corals, and encrusting corals did not differ in surface area or colony

220 density across anchoring regimes (Table S2).

221 Changes in reef rugosity associated with anchoring

222 Rugosity at sites with high anchoring activity was $40 \%$ lower than at sites with little or no

223 anchoring $\left(\mathrm{p}_{\mathrm{L}-\mathrm{H}}=0.00003, \mathrm{p}_{\mathrm{M}-\mathrm{H}}=0.009, \mathrm{p}_{\mathrm{M}-\mathrm{L}}=0.63\right)$ (Fig. 5).

224 Changes in fish density associated with anchoring

225 Mean total fish density was 55\% lower at sites with high anchoring than at sites with little or no

226 anchoring $\left(\mathrm{p}_{\mathrm{H}-\mathrm{L}}=0.005\right)$, and sites with medium anchoring activity had intermediate densities

$227\left(\mathrm{p}_{\mathrm{H}-\mathrm{M}}=0.4, \mathrm{p}_{\mathrm{L}-\mathrm{M}}=0.48\right)$ (Fig. 6). This reduction was driven by adult fish, whose density was

$22866 \%$ lower at low-anchoring sites than at high-anchoring sites $\left(\mathrm{p}_{\mathrm{H}-\mathrm{L}}=0.002\right)$, with intermediate

229 densities at medium-anchoring sites $\left(\mathrm{p}_{\mathrm{H}-\mathrm{M}}=0.2, \mathrm{p}_{\mathrm{L}-\mathrm{M}}=0.58\right)$. The density of juvenile fish did not

230 differ by anchoring level $\left(\mathrm{p}_{\mathrm{H}-\mathrm{M}}=0.2, \mathrm{p}_{\mathrm{H}-\mathrm{L}}=0.6, \mathrm{p}_{\mathrm{L}-\mathrm{M}}=0.08\right)$. Accompanying the decline in total

231 fish density was a corresponding decline in fish species richness, which was $35 \%$ lower at highly

232 anchored sites compared to sites with little or no anchoring $\left(\mathrm{p}_{\mathrm{H}-\mathrm{L}}=0.0004\right)$; and richness was

233 intermediate at sites with medium-levels of anchoring $\left(\mathrm{p}_{\mathrm{H}-\mathrm{M}}=0.6, \mathrm{p}_{\mathrm{L}-\mathrm{M}}=0.06\right)$ (Fig. 6).

234 These reductions in fish density were spread across several trophically based functional groups

235 (Table 2). Herbivores capable of removing substratum while feeding (adult scrapers and

236 excavators), were reduced in density by roughly $73 \%$ at high-anchoring sites relative to medium-

237 and low-anchoring sites $\left(\mathrm{p}_{\mathrm{H}-\mathrm{L}}=0.006, \mathrm{p}_{\mathrm{H}-\mathrm{M}}=0.4, \mathrm{p}_{\mathrm{L}-\mathrm{M}}=0.5\right)$. At our sites, excavators were

238 primarily stoplight parrotfish (Sparisoma viride), and scrapers were primarily blue parrotfish

239 (Scarus coeruleus) and queen parrotfish (Scarus vetula). Other types of adult herbivore, who

240 vary in feeding behavior but do not excavate the substratum, were $66 \%$ lower in density at high-

241 anchoring sites than elsewhere $\left(\mathrm{p}_{\mathrm{H}-\mathrm{L}}=0.002, \mathrm{p}_{\mathrm{H}-\mathrm{M}}=0.14, \mathrm{p}_{\mathrm{L}-\mathrm{M}}=0.7\right)$. These other herbivores

242 were primarily other parrotfish, surgeonfish, and damselfish and were functionally turf grazers,

243 macroalgal browsers and territorial algal/detritus feeders.

244 Other functional groups of fish that consume benthic resources also displayed reductions in

245 density associated with anchoring (Table 2). Spongivore densities were 95\% lower at highly

246 anchored sites than at low-and medium-anchoring sites $\left(\mathrm{p}_{\mathrm{H}-\mathrm{L}}=0.003, \mathrm{p}_{\mathrm{H}-\mathrm{M}}=0.4, \mathrm{p}_{\mathrm{M}-\mathrm{L}}=0.4\right)$ and

247 comprised primarily angelfish, filefish, spadefish, and boxfishes. Benthic carnivores were

248 reduced by $36 \%$ at high-anchoring sites $\left(\mathrm{p}_{\mathrm{L}-\mathrm{H}}=0.03, \mathrm{p}_{\mathrm{M}-\mathrm{H}}=0.03, \mathrm{p}_{\mathrm{M}-\mathrm{L}}=0.63\right)$. Benthic

249

250

251

252

253 carnivores at our sites included species that consume mobile invertebrates or sessile invertebrates, and some may also eat fish. This was a broad group that included wrasses, butterflyfishes, hamlets, some groupers, bass, pufferfish, grunts, goatfish, drums, snappers, trunkfish, triggerfish, mojarra, porgies, and porcupine fish. Lastly, there were also $61 \%$ fewer piscivores at high-anchoring sites than at low- and medium-anchoring sites $\left(\mathrm{p}_{\mathrm{M}-\mathrm{H}}=0.012, \mathrm{p}_{\mathrm{L}-\mathrm{H}}=\right.$ 
$\left.2540.004, \mathrm{p}_{\mathrm{M}-\mathrm{L}}=0.73\right)$. At our BVI sites, piscivores comprised mostly groupers, lizardfish and 255 lionfish.

\section{Fraction of reefs vulnerable to anchoring}

257 From the marine habitat maps we examined, we estimated 24\% of coral reef area in the British

258 Virgin Islands is leeward in exposure, although this only a rough estimate of the fraction of reef

259 that is safe to anchor near because exposure varies with the seasons and weather.

\section{Discussion}

261

262

263

264

265

266

267

268

269

270

271

272

273

274

275

276

277

278

279

280

281

282

283

284

285

286

287

288

289

290

291

292

293

294

295

296

Although we attempted to control for other factors that might impact reefs, it is difficult to reliably decouple the effects of anchoring from other human impacts. Increased boat activity is associated with more anchor damage (Fig. S3), but there may be other factors coupled to human visitation affecting reef communities in these locations. We argue that damage by snorkelers and divers from the boats is unlikely to be a major source of confounding because (1) most sites were too deep for recreational snorkelers to plausibly damage the reef, (2) most recreational diving is concentrated at other sites at which the local dive operators use moorings specifically designated for dive boats, and (3) damage symptoms commonly included smashed or overturned corals that appear too large ( $>0.5 \mathrm{~m}$ diameter) to be attributed to divers (Fig. S3). Nonetheless, some of the impacts we attribute to anchoring could also be caused by sewage discharge from boats, boat hull antifouling paint, and littering by boat users. In addition, this study presents a snapshot in time. It is possible that boating impacts have already interacted with other stressors at the site and may have diminished anchored reefs' recovery from other stressors (Carilli et al. 2009).

While anchoring impacts have been documented for soft sediments (Backhurst \& Cole, 2000), seagrass beds (Francour, Ganteaume \& Poulain, 1999; Creed \& Amado Filho, 1999; Milazzo et al., 2004) and associated taxa (Hendriks et al., 2013), we are aware of few previous studies documenting community-wide impacts associated with anchoring on coral reefs. Previous work has documented the mechanisms by which anchors damage reefs (Glynn, 1994; McManus, Reyes \& Nañola, 1997; Dinsdale \& Harriott, 2004; Fava et al., 2009), and used models to predict rates of coral-cover loss (McManus, Reyes \& Nañola, 1997; Saphier \& Hoffmann, 2005). Early empirical studies imply that impacts can be substantial. In Florida, extensive ( $20 \%$ by area) anchor damage to A. cervicornis thickets was observed (Davis, 1977), and circumstantial evidence linked anchoring to the decline of A. palmata and other corals in this area (Dustan \& Halas, 1987). In the Pacific, Edinger and co-workers (1998) argued that multiple human activities, including anchoring, affected Indonesian coastal reefs, but perhaps the strongest evidence for anchoring impacts comes from the Great Barrier Reef where, at three sites subject to frequent anchoring, symptoms of coral damage were increased, and the cover of three coral families and of soft corals was reduced relative to three equivalent low-anchoring sites (Dinsdale $\&$ Harriott, 2004).

We isolated a surprisingly substantial reduction in coral cover associated with boat anchoring in the BVI. Our study was not designed to measure the effect of anchoring against other human and natural agents of change but, for context, we note that mean coral cover at our low-anchoring sites (17.1\%) is above the recent Caribbean-wide average of $14.3 \%$, whereas cover at the high anchoring sites (9.9\%) is just above the region-wide 25\% quantile (Jackson et al., 2014). The difference in absolute coral cover between high- and low-anchoring sites $(7.2 \%)$ is also substantial relative to long-term declines in coral cover measured in the BVI ( $12 \%$ over 21 years) 
297 and region-wide (19\% over 40 years) (Jackson et al., 2014; Forrester et al., 2015a). In a related 298 BVI study, there was no obvious recovery after 11 years from the damage caused by a one-off 299 anchoring event (Forrester et al., 2015b), suggesting that the spatial gradients we measured are 300 likely to persist unless anchoring activity declines.

301 The community-wide impacts associated with anchoring appeared to comprise a mix of direct

302

303

304

305

306 and indirect effects. Abundant symptoms of damage to coral colonies at high-anchoring sites, plus the fact that impacts were most severe for corals with high vertical relief (branching, plating and mounding colonies), suggests damage from anchor chains sweeping across the reef is a major direct agent of coral loss (Davis, 1977; Forrester et al., 2015b). The same reasoning suggests that mortality from contact with anchors and chains accounts for most of the loss of sea fans at high-anchoring sites. These taxa contribute much of the vertical relief on coral reefs, so the approximate halving of their abundance explains why reef rugosity was reduced by almost half at frequently anchored sites. Because many reef fish taxa depend on three-dimensional reef structure for shelter (Luckhurst \& Luckhurst, 1978; Ault \& Johnson, 1998), the 'flattening' of highly anchored sites is a plausible explanation for reduced densities of most (5 of 7) functional groups of adult fishes. Juvenile fish densities did not differ across anchoring intensities, suggesting that juveniles may be generally less-sensitive to habitat damage associated with anchoring than adults. The lack of detectable anchoring effects on some benthic taxa (e.g. encrusting sponges, fire coral, crustose coralline and filamentous algae) may be due to their low profile and lower vulnerability to anchor damage, or to rapid recovery rates after damage. Reefs that have experienced reductions in coral cover and in the abundance of herbivorous fish commonly show elevated biomass of fleshy macroalgae (Adam et al., 2015). In the BVI, although mean cover of fleshy macroalgae almost doubled at high anchoring sites, this 'trend' was not significant suggesting that further sampling is needed to resolve the macroalgal response to anchoring.

Impacts associated with boat anchoring, relative to other human impacts, remain hard to extrapolate. We estimated that roughly $24 \%$ of BVI reefs were suitable for anchoring under most conditions. A more sophisticated vulnerability assessment indicated that $19 \%$ of the Great Barrier Reef World Heritage Site is vulnerable to anchor damage, primarily in areas where coral reefs or seagrass beds coincide with likely anchor deployment (Kininmonth et al., 2014). Because anchor damage appears to be a substantive contributor to coral reef decline in the BVI, but its effects elsewhere are poorly documented, we argue that further assessments of actual anchoring impacts in other areas are worthwhile.

The magnitude of differences between sites with and without chronic anchoring was surprising given the BVI's network of mooring buoys that dates to the 1970s (personal communication, Lianna Jarecki, Guana Science, BVI). Currently, there are 66 sites with 200 moorings managed by the National Parks Trust in the BVI (personal communication, Nancy Pascoe, National Parks Trust of the Virgin Islands), plus additional "unofficial" mooring sites. Our informal observations at high-anchoring sites with moorings revealed boats anchored on reef, often when all moorings were in use, but sometimes even when moorings were available. In other instances, boats anchored on sand in and around moorings, but their anchor chains draped across adjacent reef and swept back and forth across the reef's surface as shifting tides and winds swung the boats on their anchors. Boaters weigh multiple factors when deciding whether and where to anchor (Gray et al., 2010; McAuliffe et al., 2014), including potential damage to benthic habitats (Diedrich et al., 2013). In principle, therefore, anchor damage can be mitigated by effective local 
342 education and management programs and represents a more tractable problem than many global

343 stressors, such as ocean warming (Beeden et al., 2014).

\section{Conclusions}

345 The impacts associated with chronic boat anchoring in the BVI were of surprisingly high

346 magnitude, and were linked to a roughly $50 \%$ reduction in coral and sea fan abundance. Indirect

347 impacts on reef rugosity and on many common families of fish were of broadly similar

348 magnitude. The magnitude of these impacts was surprising, in part, because of the well-

349 developed network of mooring buoys in the area designed to reduce the frequency of anchoring.

350

351

352

353

354

355

Because the magnitude of impact was estimated based on a spatial comparison, it is hard to directly compare the effects of anchoring to those of other anthropogenic stressors whose impacts are more commonly assessed by temporal before-after comparisons. Nonetheless, we suggest that further analysis of boat anchoring effects is worthwhile and that the priorities should be, (1) estimating the magnitude of boating impacts relative to other agents of reef damage and (2) understanding how moorings can be best used to mitigate anchor damage.

\section{Acknowledgments}

357

358

359

360

361

362

363

364

365

366

367

368

369

370

371

372

373

374

375

376

377

378

379

380

We are grateful to Jessica Perreault, David Gleeson, and Kristian Dzilenski for field assistance. Earlier versions of the manuscript were improved by input from Lianna Jarecki, Jason Kolbe, Gavino Puggioni, Mary Donovan, Peggy Fong and an anonymous reviewer. Finally, thank you to the local experts in the BVI who shared their knowledge with us.

\section{Reference List}

Adam TC, Burkepile DE, Ruttenberg BI, and Paddack MJ. 2015. Herbivory and the resilience of Caribbean coral reefs: knowledge gaps and implications for management. Marine Ecology Progress Series 520:1-20.

Almada-Villela PC., Sale PF., Gold-Bouchot G., Kjerfve B. 2003. Manual of methods for the MBRS synoptic monitoring program: Selected methods for monitoring physical and biological parameters for use in the Mesoamerican region. Mesoamerican Barrier Reef Systems project (MBRS), Belize City.

Alvarez-Filip L., Dulvy NK., Gill JA., Cote IM., Watkinson AR. 2009. Flattening of Caribbean coral reefs: region-wide declines in architectural complexity. Proceedings of the Royal Society B: Biological Sciences 276:3019-3025. DOI: 10.1098/rspb.2009.0339.

Ault TR., Johnson CR. 1998. Spatially and Temporally Predictable Fish Communities on Coral Reefs. Ecological Monographs 68:25. DOI: 10.2307/2657142.

Backhurst M., Cole R. 2000. Biological impacts of boating at Kawau Island, north-eastern New Zealand. Journal of Environmental Management 60:239-251. DOI: 10.1006/jema.2000.0382.

Bakus GR. 2002. Quantitaive analysis of marine biological communities: field biology and environment. Hoboken, New Jersey: Wiley Interscience.

Beeden R., Maynard J., Johnson J., Dryden J., Kininmonth S., Marshall P. 2014. No-anchoring areas reduce coral damage in an effort to build resilience in Keppel Bay, southern Great 
381

382

383

384

385

386

387

388

389

390

391

392

393

394

395

396

397

398

399

400

401

402

403

404

405

406

407

408

409

410

411

412

413

414

415

416

417

418

419
Barrier Reef. Australasian Journal of Environmental Management 21:311-319. DOI: 10.1080/14486563.2014.881307.

Bolker BM. 2008. Ecological models and data in R. Princeton, N.J: Princeton University Press.

Burgin S., Hardiman N. 2011. The direct physical, chemical and biotic impacts on Australian coastal waters due to recreational boating. Biodiversity and Conservation 20:683-701. DOI: $10.1007 / \mathrm{s} 10531-011-0003-6$.

Burke L., Reytar K., Spalding M., Perry A. 2011. Reefs at Risk Revisited. Washington, DC: World Resources Institute.

Carilli, J. E., Norris, R. D., Black, B. A., Walsh, S. M. McField, M. 2009. Local stressors reduce coral resilience to bleaching. PLOS One 4:e6324. DOI: 10.1371/journal.pone.0006324.

Creed JC., Amado Filho GM. 1999. Disturbance and recovery of the macroflora of a seagrass (Halodule wrightii Ascherson) meadow in the Abrolhos Marine National Park, Brazil: an experimental evaluation of anchor damage. Journal of Experimental Marine Biology and Ecology 235:285-306. DOI: 10.1016/S0022-0981(98)00188-9.

Davenport J., Davenport JL. 2006. The impact of tourism and personal leisure transport on coastal environments: A review. Estuarine, Coastal and Shelf Science 67:280-292. DOI: 10.1016/j.ecss.2005.11.026.

Davis GE. 1977. Anchor damage to a coral reef on the coast of Florida. Biological Conservation 11:29-34. DOI: 10.1016/0006-3207(77)90024-6.

Diedrich A., Terrados J., Arroyo NL., Balaguer P. 2013. Modeling the influence of attitudes and beliefs on recreational boaters' use of buoys in the Balearic Islands. Ocean \& Coastal Management 78:112-120. DOI: 10.1016/j.ocecoaman.2013.02.027.

Dinsdale EA., Harriott VJ. 2004. Assessing Anchor Damage on Coral Reefs: A Case Study in Selection of Environmental Indicators. Environmental Management 33:126-139. DOI: 10.1007/s00267-003-3056-9.

Dobson A., Lodge D., Alder J., Cumming GS., Keymer J., McGlade J., Mooney H., Rusak JA., Sala O., Wolters V., others 2006. Habitat loss, trophic collapse, and the decline of ecosystem services. Ecology 87:1915-1924.

Dustan P., Halas JC. 1987. Changes in the reef-coral community of Carysfort Reef, Key Largo, Florida: 1974 to 1982. Coral Reefs 6:91-106.

Edinger EN., Jompa J., Limmon GV., Widjatmoko W., Risk MJ. 1998. Reef degradation and coral biodiversity in Indonesia: effects of land-based pollution, destructive fishing practices and changes over time. Marine Pollution Bulletin 36:617-630.

Ehrlich PR., Wilson E 0. 1991. Biodiversity Studies: Science and Policy. Science 253:758-762. DOI: 10.1126/science.253.5021.758.

Environmental Systems Research Institute (ESRI) 2011. ArcGIS Desktop. Redlands, CA: Environmental Systems Research Institute.

Fava F., Ponti M., Scinto A., Calcinai B., Cerrano C. 2009. Possible effects of human impacts on epibenthic communities and coral rubble features in the marine Park of Bunaken

Peer] reviewing PDF | (2019:01:34489:1:1:NEW 6 Apr 2019) 
429

430

431

432

433

434

435

436

437

438

439

440

441

442

443

444

445

446

447

448

449

450

451

452

453

454

455

456

457

458

(Indonesia). Estuarine, Coastal and Shelf Science 85:151-156. DOI: 10.1016/j.ecss.2009.02.028.

Forrester G., Baily P., Conetta D., Forrester L., Kintzing E., Jarecki L. 2015a. Comparing monitoring data collected by volunteers and professionals shows that citizen scientists can detect long-term change on coral reefs. Journal for Nature Conservation 24:1-9. DOI: 10.1016/j.jnc.2015.01.002.

Forrester GE., Flynn RL., Forrester LM., Jarecki LL. 2015b. Episodic Disturbance from Boat Anchoring Is a Major Contributor to, but Does Not Alter the Trajectory of, Long-Term Coral Reef Decline. PloS one 10:e0144498.

Francour P., Ganteaume A., Poulain M. 1999. Effects of boat anchoring in Posidonia oceanica seagrass beds in the Port-Cros National Park(north-western Mediterranean Sea). Aquatic conservation: marine and freshwater ecosystems 9:391-400.

Gardner TA., Côté IM., Gill JA., Grant A., Watkinson AR. 2003. Long-term region-wide declines in Caribbean corals. Science 301:958-960.

Glynn PW. 1994. State of coral reefs in the Galápagos Islands: natural vs anthropogenic impacts. Marine Pollution Bulletin 29:131-140.

Goenaga C. 1991. The State of Coral Reefs in the Wider Caribbean. Interciencia 16:12-20.

Graham NAJ., Wilson SK., Pratchett MS., Polunin NVC., Spalding MD. 2009. Coral mortality versus structural collapse as drivers of corallivorous butterflyfish decline. Biodiversity and Conservation 18:3325-3336. DOI: 10.1007/s10531-009-9633-3.

Gray DL., Canessa R., Rollins R., Keller CP., Dearden P. 2010. Incorporating Recreational Users into Marine Protected Area Planning: A Study of Recreational Boating in British Columbia, Canada. Environmental Management 46:167-180. DOI: 10.1007/s00267-0109479-1.

Halpern BS, and Floeter SR. 2008. Functional diversity responses to changing species richness in reef fish communities. Marine Ecology Progress Series 364:147-156. DOI: 10.3354/meps07553

Hendriks IE., Tenan S., Tavecchia G., Marbà N., Jordà G., Deudero S., Álvarez E., Duarte CM. 2013. Boat anchoring impacts coastal populations of the pen shell, the largest bivalve in the Mediterranean. Biological Conservation 160:105-113. DOI: 10.1016/j.biocon.2013.01.012.

Jackson JBC., Donovan MK., Cramer KL., Lam VV. (eds.) 2014. Status and Trends of Caribbean Coral Reefs: 1970-2012. Gland, Switzerland: Global Coral Reef Monitoring Network, IUCN.

Johnstone RW., Muhando CA., Francis J. 1998. The Status of the Coral Reefs of Zanzibar: One Example of a Regional Predicament. Ambio 27:700-707.

Kininmonth S., Lemm S., Malone C., Hatley T. 2014. Spatial vulnerability assessment of anchor damage within the Great Barrier Reef World Heritage Area, Australia. Ocean \& Coastal Management 100:20-31. DOI: 10.1016/j.ocecoaman.2014.07.003. 
459

460

461

462

463

464

465

466

467

468

469

470

471

472

473

474

475

476

477

478

479

480

481

482

483

484

485

486

487

488

489

490

491

492

493

494

495

496

497

498

Lewis AR. 1998. Effects of experimental coral disturbance on the population dynamics of fishes on large patch reefs. Journal of Experimental Marine Biology and Ecology 230:91-110.

Lirman D., Fong P. 2007. Is proximity to land-based sources of coral stressors an appropriate measure of risk to coral reefs? An example from the Florida Reef Tract. Marine Pollution Bulletin 54:779-791. DOI: 10.1016/j.marpolbul.2006.12.014.

Luckhurst BE., Luckhurst K. 1978. Analysis of the influence of substrate variables on coral reef fish communities. Marine Biology 49:317-323.

McAuliffe S., Potts J., Canessa R., Baily B. 2014. Establishing attitudes and perceptions of recreational boat users based in the River Hamble Estuary, UK, towards Marine Conservation Zones. Marine Policy 45:98-107. DOI: 10.1016/j.marpol.2013.11.009.

McCormick MI. 1994. Comparison of field methods for measuring surface topography and their associations with a tropical reef fish assemblage. Marine ecology progress series. 112:87-96.

McManus JW., Reyes J., Nañola J. 1997. Effects of some destructive fishing methods on coral cover and potential rates of recovery. Environmental management 21:69-78.

Milazzo M., Badalamenti F., Ceccherelli G., Chemello R. 2004. Boat anchoring on Posidonia oceanica beds in a marine protected area (Italy, western Mediterranean): effect of anchor types in different anchoring stages. Journal of Experimental Marine Biology and Ecology 299:51-62. DOI: 10.1016/j.jembe.2003.09.003.

Naeem S., Thompson LJ., Lawler SP., Lawton JH., Woodfin RM. 1994. Declining biodiversity can alter the performance of ecosystems. Nature 368:734-737.

National Oceanic and Atmospheric Administration (NOAA), National Ocean Service, Office of Response and Restoration, Hazardous Materials Response Division, Seattle, Washington, United States Environmental Protection Agency, United States Coast Guard, U.S. Virgin Islands Department of Planning and Natural Resources, British Virgin Islands Conservation and Fisheries Department, United States Department of the Interior 2001. U.S. Virgin Islands and British Virgin Islands ESI: BENTHIC (Benthic Marine Habitats).

R Core Team 2013. R: a language and environment for statistical computer. Vienna, Austria: R Foundation for Statistical Computing.

Saphier AD., Hoffmann TC. 2005. Forecasting models to quantify three anthropogenic stresses on coral reefs from marine recreation: Anchor damage, diver contact and copper emission from antifouling paint. Marine Pollution Bulletin 51:590-598. DOI: 10.1016/j.marpolbul.2005.02.033.

Schutte V., Selig E., Bruno J. 2010. Regional spatio-temporal trends in Caribbean coral reef benthic communities. Marine Ecology Progress Series 402:115-122. DOI: 10.3354/meps08438.

Strong CW. 1966. An Improved Method of Obtaining Density from Line-Transect Data. Ecology 47:311. DOI: $10.2307 / 1933781$.

Wilkinson C. (ed.) 2008. Status of coral reefs of the world: 2008. Townsville, Australia: Global Coral Reef Monitoring Network and Reef and Rainforest Research Centre.

Peer] reviewing PDF | (2019:01:34489:1:1:NEW 6 Apr 2019) 
499 Wilkinson CR., Buddemeier RW. 1994. Global Climate Change and Coral Reefs: Implications 500 for People and Reefs: Report of the UNEP-IOC-ASPEI-IUCN Global Task Team on the 501 Implications of Climate Change on Coral Reefs. IUCN.

502

503 


\section{Table $\mathbf{1}$ (on next page)}

Percent cover of major benthic taxa at sites with different levels of anchoring.

Mean cover $( \pm 95 \% \mathrm{Cl})$ at sites with low $(\mathrm{L})$, medium $(\mathrm{H})$ and high $(\mathrm{H})$ levels of anchoring, and the proportional change between high and low levels. The last column indicates which groups are significantly different from each other using a multiple comparison test (see Methods for further details). 


\section{Table 1:}

\section{Percent cover of major benthic taxa at sites with different levels of anchoring.}

3 Mean cover $( \pm 95 \% \mathrm{CI})$ at sites with low $(\mathrm{L})$, medium $(\mathrm{H})$ and high $(\mathrm{H})$ levels of anchoring, and 4 the proportional change between high and low levels. The last column indicates which groups 5 are significantly different from each other using a multiple comparison test (see Methods for 6 further details).

\begin{tabular}{|l|c|c|c|c|c|}
\hline Taxonomic Group & $\begin{array}{c}\text { Low } \\
\text { anchoring } \\
\text { sites (\% } \\
\text { cover) }\end{array}$ & $\begin{array}{c}\text { Medium } \\
\text { anchoring } \\
\text { sites (\% } \\
\text { cover) }\end{array}$ & $\begin{array}{c}\text { High } \\
\text { anchoring } \\
\text { sites (\% } \\
\text { cover) }\end{array}$ & $\begin{array}{c}\text { Proportional } \\
\text { change in } \\
\text { cover (H-L) /L }\end{array}$ & $\begin{array}{c}\text { Sites } \\
\text { that } \\
\text { differed }\end{array}$ \\
\hline Hard Coral & $17.05 \pm 2.4$ & $16.06 \pm 2.3$ & $9.91 \pm 1.9$ & -0.42 & $\begin{array}{c}\mathrm{H}-\mathrm{L}, \mathrm{H}- \\
\mathrm{M}\end{array}$ \\
\hline Fire Coral & $3.65 \pm 0.5$ & $3.09 \pm 0.9$ & $2.73 \pm 0.5$ & -0.25 & None \\
\hline Sea Fan & $12.78 \pm 5.9$ & $4.71 \pm 3.9$ & $5.00 \pm 4.0$ & -0.61 & $\mathrm{H}-\mathrm{L}, \mathrm{M}-\mathrm{L}$ \\
\hline $\begin{array}{l}\text { Soft Branching } \\
\text { Coral }\end{array}$ & $18.58 \pm 6.3$ & $19.15 \pm 6.4$ & $13.20 \pm 5.7$ & -0.29 & None \\
\hline Sponges: Erect & $3.77 \pm 2.8$ & $5.93 \pm 4.7$ & $1.86 \pm 0.9$ & -0.51 & None \\
\hline Sponges: Encrusting & $5.07 \pm 1.5$ & $3.77 \pm 2.7$ & $2.93 \pm 1.6$ & -0.42 & None \\
\hline Algae: Fleshy & $12.85 \pm 5.8$ & $14.79 \pm 6.1$ & $20.74 \pm 6.7$ & 0.61 & None \\
\hline Algae: Calcareous & $2.15 \pm 4.6$ & $0.70 \pm 1.0$ & $2.61 \pm 3.7$ & 0.21 & None \\
\hline Algae: Crustose & $8.69 \pm 6.5$ & $6.95 \pm 2.2$ & $7.47 \pm 3.8$ & -0.14 & None \\
\hline Algae: Filamentous & $1.25 \pm 0.7$ & $2.65 \pm 3.6$ & $2.33 \pm 2.0$ & 0.86 & None \\
\hline Dead Coral & $2.57 \pm 2.0$ & $2.80 \pm 3.7$ & $6.47 \pm 3.55$ & 1.52 & None \\
\hline
\end{tabular}




\section{Table 2 (on next page)}

Densities of major fish functional groups at sites with different levels of anchoring.

Mean fish density $\pm 95 \% \mathrm{Cl}$ at sites with low $(\mathrm{L})$, medium $(\mathrm{H})$ and high $(\mathrm{H})$ levels of anchoring, and the proportional change between high and low levels. The last column indicates which groups are significantly different from each other using a multiple comparison test (see Methods for further details). 


\section{Table 2:}

2 Densities of major fish functional groups at sites with different levels of 3 anchoring.

4 Mean fish density $\pm 95 \%$ CI at sites with low (L), medium $(\mathrm{H})$ and high $(\mathrm{H})$ levels of anchoring, 5 and the proportional change between high and low levels. The last column indicates which

6 groups are significantly different from each other using a multiple comparison test (see Methods

7 for further details).

\begin{tabular}{|l|c|c|c|c|c|}
\hline $\begin{array}{l}\text { Fish Functional } \\
\text { Group }\end{array}$ & $\begin{array}{c}\text { Low } \\
\text { anchoring } \\
\text { sites } \\
\left(\# / 45 \mathbf{m}^{\mathbf{2}}\right)\end{array}$ & $\begin{array}{c}\text { Medium } \\
\text { anchoring } \\
\text { sites } \\
\left(\# / 45 \mathbf{m}^{\mathbf{2}}\right)\end{array}$ & $\begin{array}{c}\text { High } \\
\text { anchoring } \\
\text { sites } \\
\left(\# / 45 \mathbf{m}^{\mathbf{2}}\right)\end{array}$ & $\begin{array}{c}\text { Proportional } \\
\text { change in } \\
\text { density (H-L) } \\
/ \mathbf{L}\end{array}$ & $\begin{array}{c}\text { Sites that } \\
\text { differed }\end{array}$ \\
\hline $\begin{array}{l}\text { Scrapers and } \\
\text { excavators }\end{array}$ & $2.84 \pm 0.39$ & $1.94 \pm 0.77$ & $0.75 \pm 0.4$ & -0.73 & $\mathrm{H}-\mathrm{L}$ \\
\hline Other herbivores & $43.25 \pm 4.72$ & $34.92 \pm 9.34$ & $13.69 \pm 4.86$ & -0.68 & $\mathrm{H}-\mathrm{L}$ \\
\hline Piscivores & $3.11 \pm 2.21$ & $2.73 \pm 1.94$ & $1.21 \pm 0.86$ & -0.61 & $\mathrm{H}-\mathrm{L}, \mathrm{H}-\mathrm{M}$ \\
\hline Spongivores & $0.457 \pm 0.38$ & $0.23 \pm 0.32$ & $0.025 \pm 0.08$ & -0.94 & $\mathrm{H}-\mathrm{L}$ \\
\hline $\begin{array}{l}\text { Benthic } \\
\text { Carnivores }\end{array}$ & $12.86 \pm 6.17$ & $14.63 \pm 7.02$ & $8.26 \pm 3.97$ & -0.35 & $\mathrm{H}-\mathrm{L}, \mathrm{H}-\mathrm{M}$ \\
\hline Planktivores & $19.85 \pm$ & $12.86 \pm 10.1$ & $6.86 \pm 6.59$ & -0.65 & $\mathrm{None}$ \\
\hline Omnivores & $1.42 \pm 0.73$ & $1.96 \pm 1.18$ & $1.62 \pm 1.66$ & 0.14 & None \\
\hline
\end{tabular}




\section{Figure 1}

Locations of reefs surveyed in the British Virgin Islands.

Sites are coded to indicate whether they categorized as experiencing high, medium, or low frequency of anchoring. Sites were selected in 10 groups (numbered and circled) that were close in proximity.
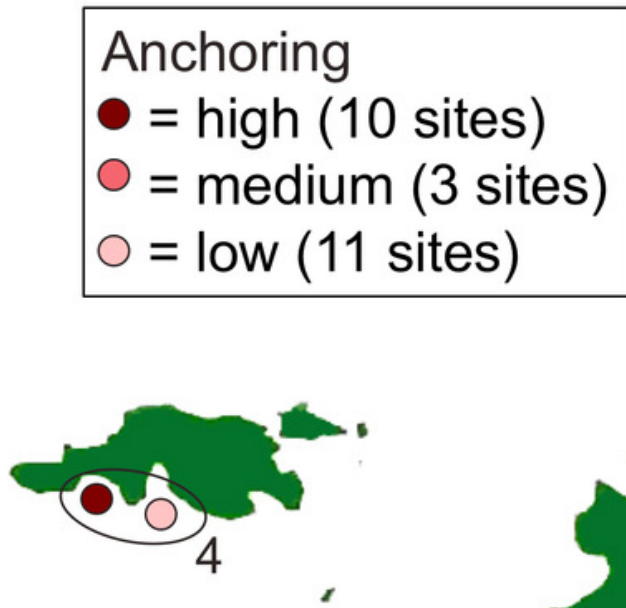

$4 \mathrm{~km}$

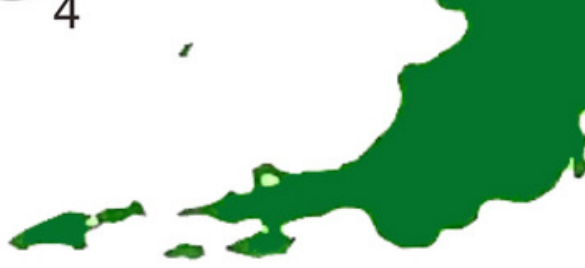

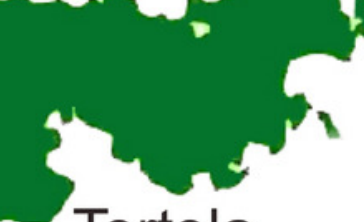
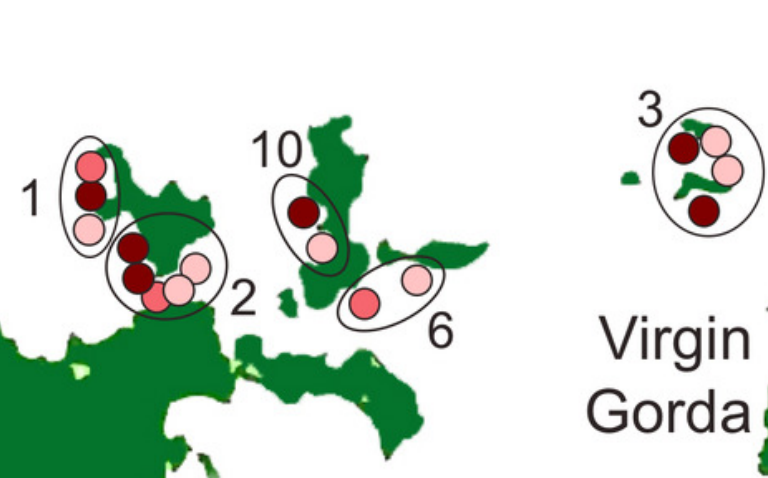

$\therefore 5$

Virgin

Gorda Tortola
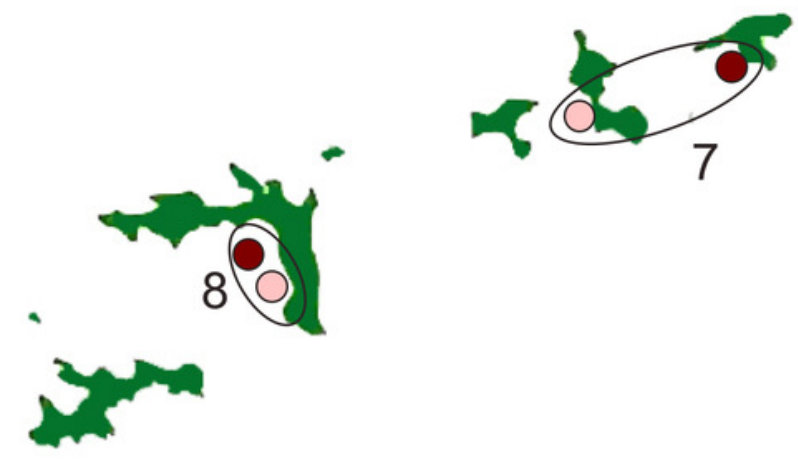
Figure 2

Anchoring activity observed using satellite imagery.

Sites were classified as high, medium or low anchoring based on expert opinion. This classification was checked by counting anchored boats at each site. Plotted are means $( \pm \mathrm{SE})$ and letters above bars indicate significant differences based on a multiple comparison test (means that do not differ share a letter). Map Data from GoogleEarth and DigitalGlobe.

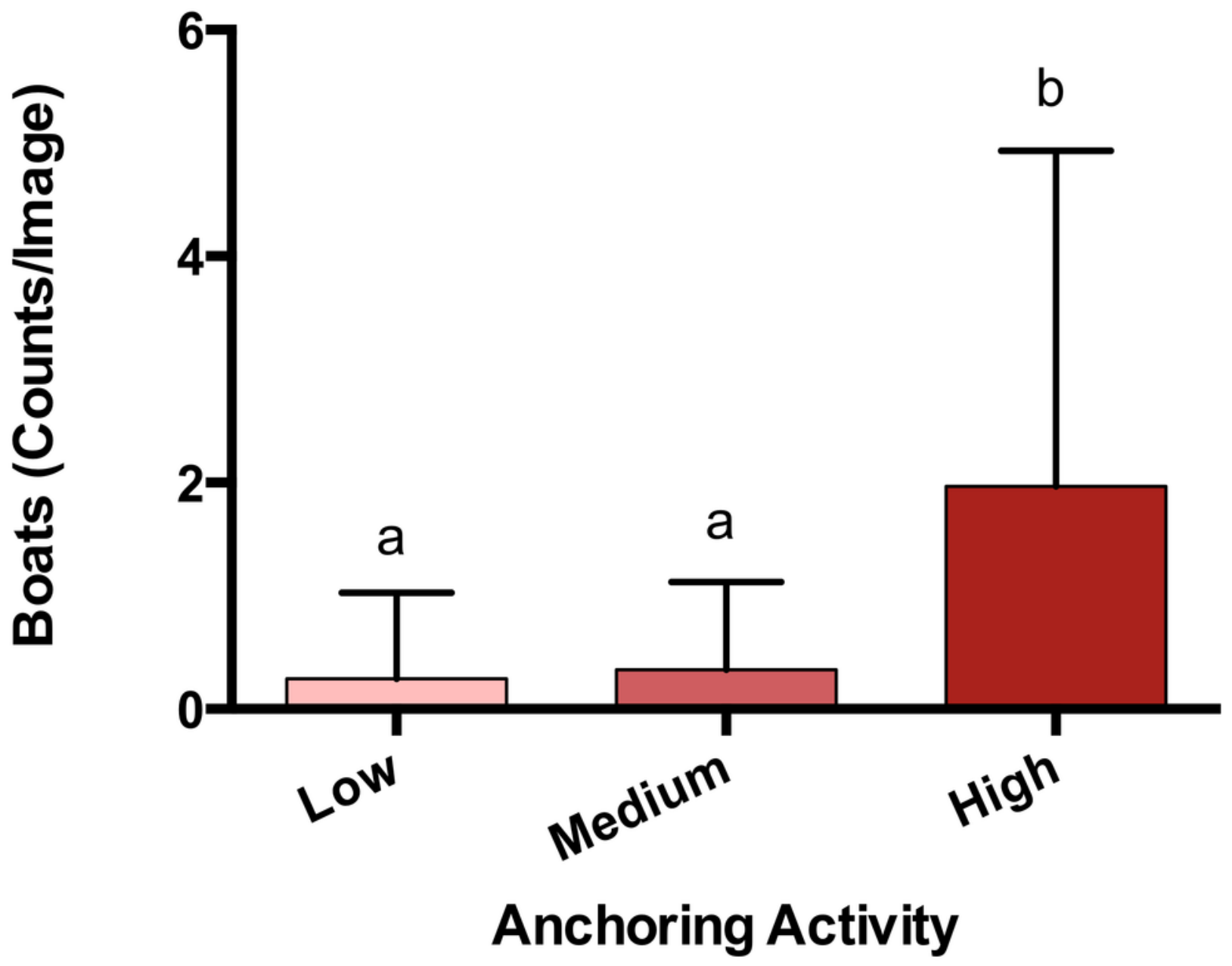


Figure 3

Hard coral and sea fan cover differ across a gradient of anchoring activity.

Means ( \pm SE) of proportional bottom cover for scleractinian corals (left) and sea fans (right).

For each taxon, letters above bars indicate significant differences based on a multiple comparison test (means that do not differ share a letter).

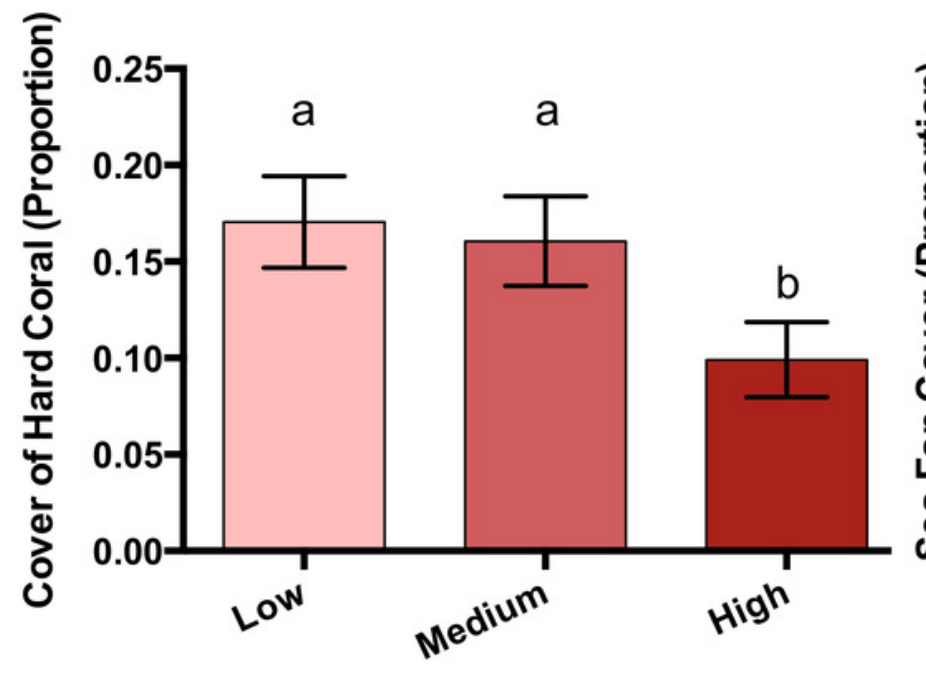

Anchoring Activity

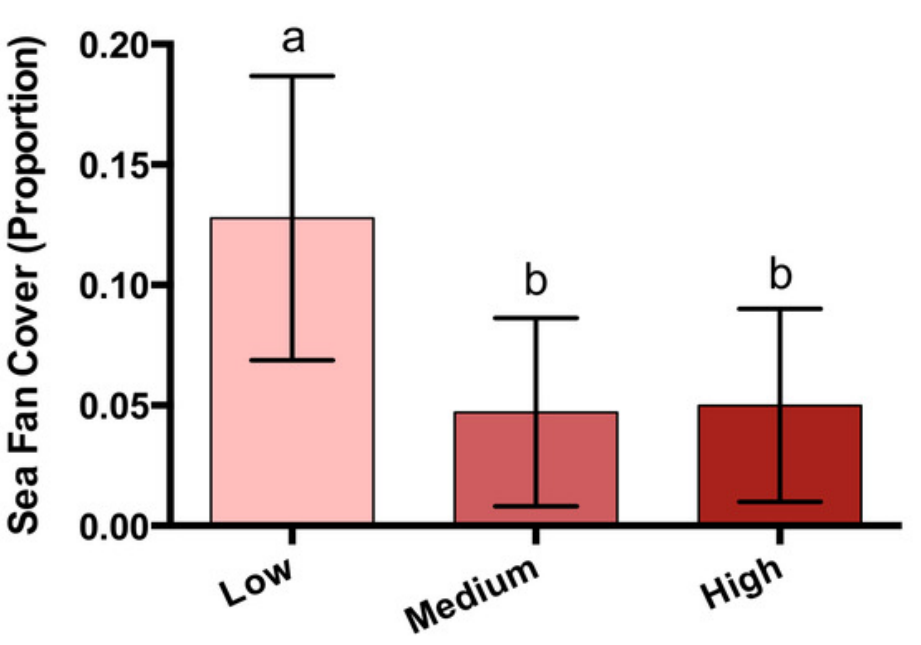

Anchoring Activity 
Figure 4

Coral diversity, abundance and size differ across a gradient of anchoring activity.

Plotted are means ( \pm SE) of (A) Coral colony surface area, (B) coral colony density, (C) coral species richness and (D) coral abundance. Letters above bars indicate significant differences based on a multiple comparison test (means that do not differ share a letter).
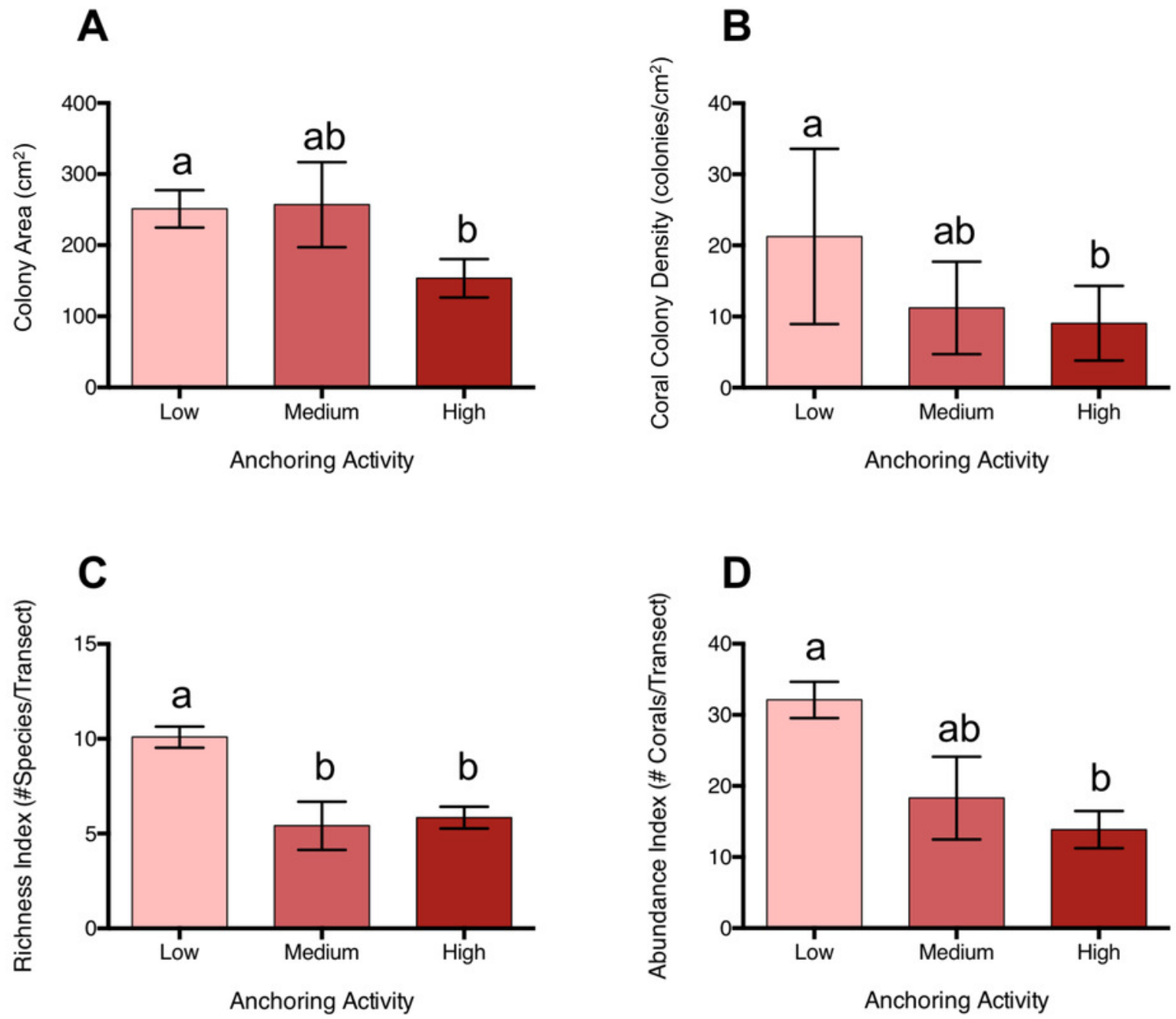
Figure 5

Rugosity differs across a gradient of anchoring activity.

Plotted are means ( $\pm \mathrm{SE}$ ) of reef rugosity and letters above bars indicate significant differences based on a multiple comparison test (means that do not differ share a letter).

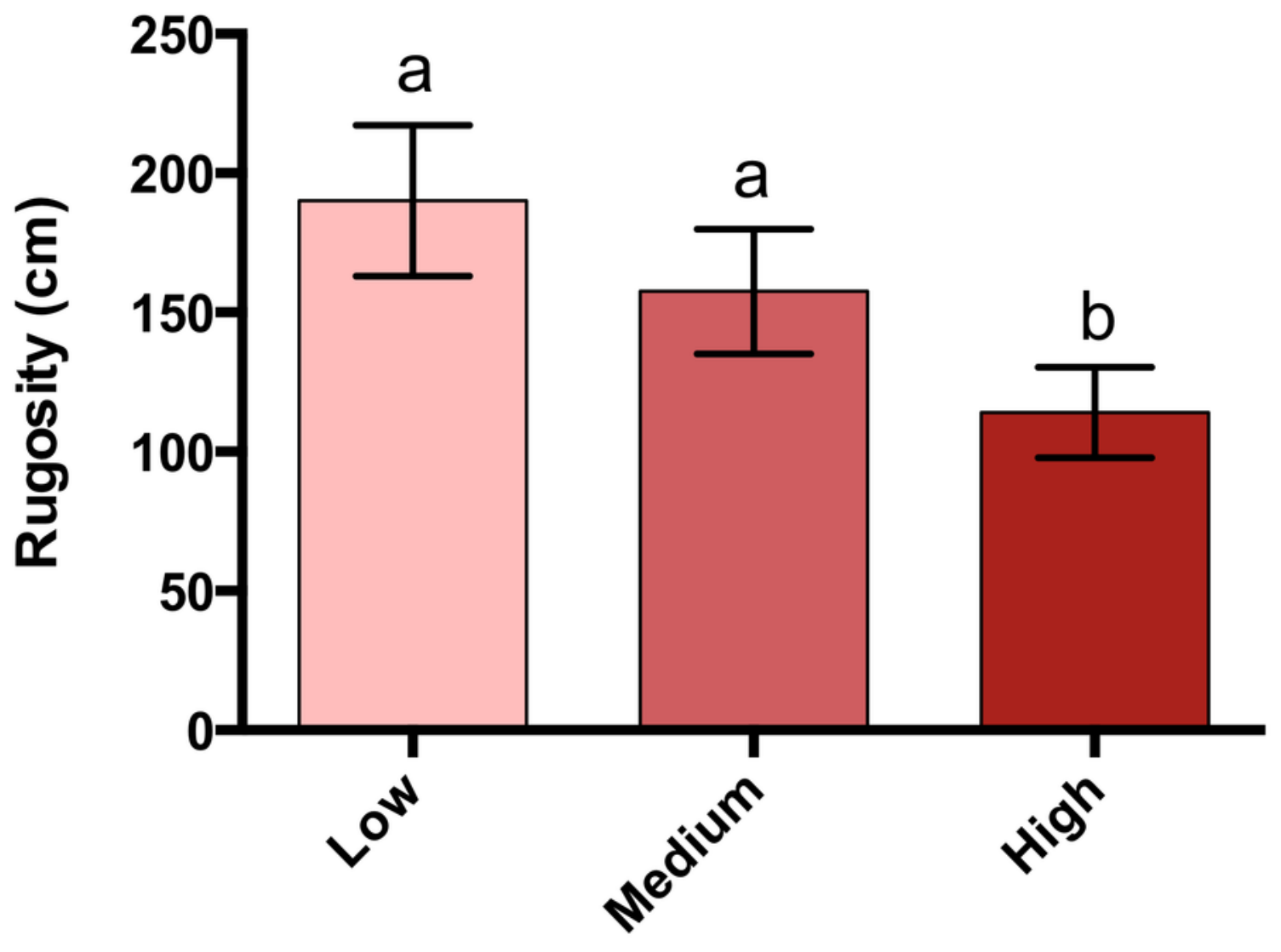

Anchoring Activity 
Figure 6

Fish abundance and diversity differ across a gradient of anchoring activity.

Plotted are means ( \pm SE) of fish density (left) and species richness (right). Letters above bars indicate significant differences based on a multiple comparison test (means that do not differ share a letter).

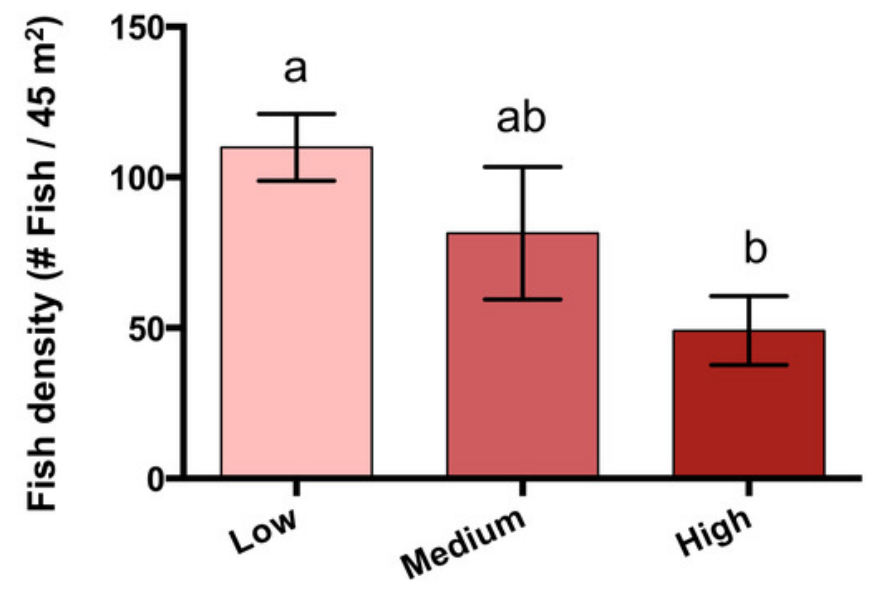

Anchoring Activity

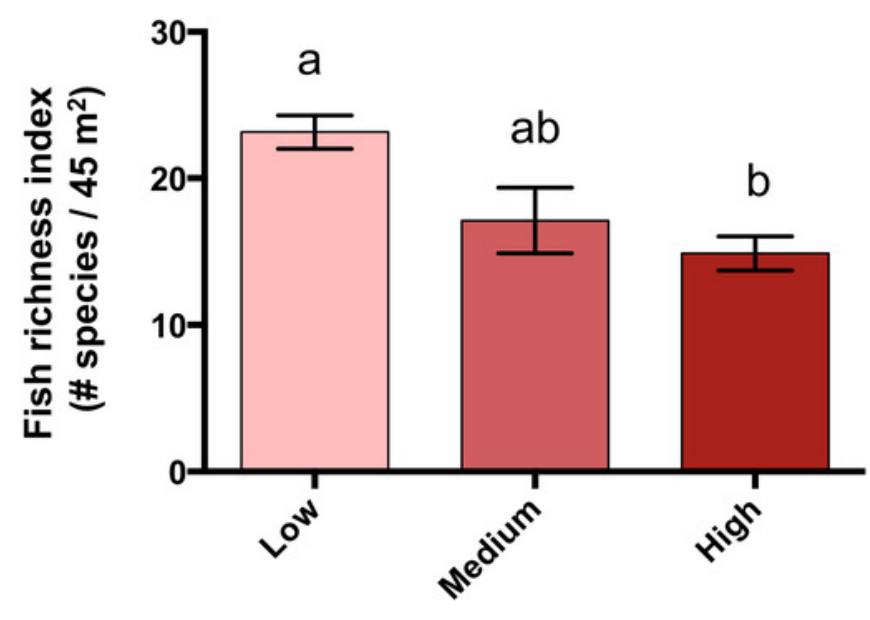

Anchoring Activity 